INVESTIGACIONES

\title{
Significaciones imaginarias atópicas de deseo. Una aproximación desde los jóvenes urbanos
}

Atopic imaginary conceptions of desire. An approach from the urban youth

\author{
Significações imaginárias atópicas de desejo. \\ Uma abordagem a partir de jovens urbanos
}

Deibar René Hurtado Herrera, ${ }^{a}$ María Andrea Simmonds Tabbert ${ }^{b}$

${ }^{a}$ Universidad del Cauca, Facultad de Ciencias Naturales, Exactas y de la Educación - Antiguo Liceo; Grupo de Investigación Urdimbre. Telf.: (57) 8209800 Ext. 2306. Correo electrónico: deibarh@yahoo.es

${ }^{\mathrm{b}}$ CINDE, Departamento de Educación y Pedagogía; Grupo de investigación Urdimbre; Universidad del Cauca. Teléfono (57) 8209800 Ext. 2350. Correo electrónico: masimmonds@unicauca.edu.co

\section{RESUMEN}

Este artículo se deriva de la investigación: "La configuración de significaciones imaginarias del deseo en jóvenes urbanos de la ciudad de Popayán”. Esta investigación pretendió comprender las significaciones imaginarias de deseo, mostrando cómo para ello es necesario urdir entramados de interdependencia a partir de las prácticas de subjetivación y de la experiencia del mundo de las y los jóvenes. Este ejercicio comprensivo mostró además cómo el skate bording, la capoeira, el teatro, el death metal y la práctica política en el movimiento estudiantil, se convierten en espacios de libertad transitoria y en campo de posibilidad para la configuración de imaginarios sociales.

Palabras clave: significaciones imaginarias, imaginarios, jóvenes, deseo.

\begin{abstract}
This article arises from a research on "the construction of imaginary meanings of desire in urban young people of Popayán city". This research on the construction of imaginary meanings of desire has implied the weaving of links of interdependence connected to the experiences of youth and their practices of subjectivity. This comprehensive exercise shows how skate boarding, capoeira, theater, death metal, and the political practice in the students' movement become spaces of transitional freedom which make possible the configuration of imaginary meanings.

Key words: imaginary significations, imaginary, young people, desire.
\end{abstract}

\section{RESUMO}

Derivado da pesquisa: "A configuração de significações imaginárias do desejo em jovens urbanos Popayan" a qual buscou compreender as significações imaginárias do desejo, mostrando como é necessário para isso entrelaçar teias de interdependência a partir das práticas de subjetivação e de experiência de mundo dos jovens. Este exercício compreensivo também mostrou como o skate, a capoeira, o teatro, o death metal e a prática política no movimento estudantil se convertem em espaços de liberdade transitória e em campo de possibilidade para a configuração de imaginários sociais.

Palavras chave: significações imaginárias, imaginários, jovens, desejo. 


\section{METODOLOGÍA}

\subsection{TIPO DE ESTUDIO}

La investigación realizada se ubicó dentro del enfoque cualitativo de investigación social, dado que comprendió las significaciones imaginarias en el contexto histórico donde estas se producían, pero también desde el mundo de la vida de las y los jóvenes. Nuestro interés estuvo en comprender las prácticas sociales y la construcción de realidad social desde las perspectivas de los propios actores, desde su cotidianidad y desde sus vivencias.

De acuerdo a las necesidades de la investigación, se optó por el principio de complementariedad (Murcia y Jaramillo, 2000), debido a que los imaginarios de deseo eran múltiples y se requerían de diferentes metodologías que han sido utilizadas por estudios emergentes cualitativos. La complementariedad es asumida en primer lugar como principio, en la medida en que recurre a nivel teórico a dar orientaciones epistemológicas para comprender la complejidad de la (s) realidad (es) sociales; la otra perspectiva de complementariedad, podría ubicarse en el diseño al apoyar la interpretación de sentido en los diferentes momentos del proceso, desde la teoría sustantiva y desde la teoría formal con pretensión de validez y, por último, al optar por apoyarse en diferentes tradiciones metodológicas, expuesta en textos como Etnografía reflexiva (Hammersley y Atkinson, 1994), Historia de vida (Creswell, 1998) y Teoría fundada (Strauss y Corbin, 2002), los que permiten la utilización de herramientas propias de ellas.

\subsection{TÉCNICAS E INSTRUMENTOS}

Se realizaron en un primer momento cinco grupos focales con distintos grupos de jóvenes en la ciudad de Popayán. ${ }^{1}$ La información recogida fue sistematizada utilizando teoría fundada y con las categorías emergentes se procedió a desarrollar observación participante de las prácticas culturales seleccionadas, ${ }^{2}$ diez historias de vida de los informantes claves, entrevistas en profundidad y la realización de un dibujo que fue por ellos posteriormente descrito. Toda la información recogida fue sistematizada a través de la utilización de teoría fundada y una vez se realizó la interpretación de sentido y se definieron categorías, estas fueron compartidas con los informantes claves buscando darle mayor confiabilidad a nuestra interpretación y retroalimentarse con sus aportes.

\subsection{TIPO DE ANÁLISIS Y PROCESAMIENTO DE LA INFORMACIÓN}

El procesamiento se hizo en forma constante; es decir, desde las primeras observaciones hasta el análisis intensivo del trabajo de campo. En el procesamiento de los datos se tuvieron en cuenta elementos metodológicos propuestos por Taylor y Bogdam (1998) como: a) Descubrimiento en progreso. b) Codificación: modo sistemático de desarrollar,

\footnotetext{
La naturaleza de los grupos fue la siguiente: prácticantes de skate boarding, de capoeira, un grupo de jóvenes cristianos, otro de estudiantes universitarios y un "parche" (grupo) de amigos del estrato 2 bajo. Además, un grupo de estudiantes universitarios y de jóvenes cristianos que se consideraron tratando de ver si existían diferencias marcadas en relación con otros grupos que los convocaba alguna motivación no institucional.

2 Las prácticas culturales juveniles seleccionadas se escogieron bajo el criterio que en ellas se realizara algún tipo de producto cultural, bien fuera corpóreo, musical, escrito o que mezclara las anteriores expresiones.
} 
refinar y buscar categorías que den cuenta de la información obtenida. c) Relativización de los datos.

\section{SIGNIFICACIONES IMAGINARIAS ATÓPICAS DE DESEO ${ }^{3}$}

Foucault (1979: 3) en el prefacio del libro Las palabras y las cosas (1996), contrapone al concepto de utopías el concepto de heterotopías. Las utopías son presentadas por él como aquella nostalgia de un "lugar común" que consuela: «pues si no tienen un lugar real, se desarrollan en un espacio maravilloso y liso; despliegan ciudades de amplias avenidas, jardines bien dispuestos, comarcas fáciles, aún si su acceso es quimérico», permitiendo las fábulas y los discursos. Contrariamente, y a partir de la idea y la experiencia de lo atópico, las heterotopías:

Inquietan, sin duda porque minan secretamente el lenguaje, porque impiden nombrar esto y aquello, porque rompen los nombres comunes o los enmarañan, porque arruinan de antemano la "sintaxis" y no sólo la que construye las frases —aquella menos evidente que hace mantener juntas (unas al lado o frente de otras) a las palabras y las cosas [...] Las heterotopías (como las que con tanta frecuencia se encuentran en Borges) secan el propósito, detienen las palabras en sí mismas, desafían, desde su raíz, toda posibilidad de gramática; desatan los mitos y envuelven en esterilidad el lirismo de las frases (Foucault, 1979: 3).

El carácter atópico del deseo hace referencia a la dificultad de encontrar un lugar común para las significaciones imaginarias de deseo, pero al mismo tiempo para mostrar la contingencia de la forma de mirar estas significaciones, de la manera en cómo han sido categorizadas a partir de esta investigación. Resaltar lo atópico y lo heterotópico de ellas implica dar espacio para los movimientos, las mixturas y las hibridaciones con otras significaciones imaginarias. Igualmente, las interdependencias de los diferentes espacios vitales en la configuración de esos entramados que vinculan prácticas de subjetivación, temporalidades y clase social.

Lo atópico, como bellamente lo expresara Camille Domoulié (2005: 296), es:

Eros, hijo de Poros y de Penia: sin morada fija, duerme al aire libre, en los márgenes y en las calles como contaba Diotima. Daimon, no es mortal ni inmortal, ni erudito ni sabio, ni rico ni pobre, es un hechicero, un mago, un sofista. Al mismo tiempo en toda parte y en ninguna, su lugar es un no lugar.

Las significaciones imaginarias de deseo de los jóvenes nos muestran su carácter atópico, el entramado de aquello que se instituyó y se sigue instituyendo por diferentes medios como deseo, en sus relaciones con el placer, con la sexualidad y el erotismo. De igual forma, las nuevas significaciones de deseo que se vinculan con las situaciones vividas cotidianamente en las prácticas, con los retos y los límites a los cuales se desafían. En este sentido, las categorías que desarrollaremos a continuación tienen el propósito de mostrar

En tal sentido, investigar sobre imaginarios es: «dar cuenta de las significaciones y de forma complementaria de los imaginarios sociales, a partir de los cuales se teje la urdimbre que conocemos como realidad social o como realidades sociales, de los procesos de creación que producen desplazamientos de sentido o sobre aquello que permite configurar sentido, de lo inexistente que emerge desde la imaginación radical o de algo que ya está instituido» (Hurtado, 2007: 14). 
ese juego de relaciones, esa urdimbre interpretativa de significaciones imaginarias que se mixturan en estas prácticas de subjetivación. Mixturas que nos permiten ver como distinciones filosóficas que analíticamente son irreconciliables, en la práctica se amalgaman o sirven de base para la emergencia de aquello que precisamente era considerado su opuesto.

\subsection{SIGNIFICACIONES IMAGINARIAS DE DESEO. EL ENCUADRE TEÓRICO DE LOS HALLAZGOS}

Inicialmente, abordaremos las significaciones imaginarias del deseo que se mueven entre la potencia y la carencia. Este movimiento se hace evidente a partir de la mixtura de significaciones que vinculan la vivencia del límite (el deseo como potencia), con las significaciones que relacionan al deseo con el querer/tener; o sea, con la carencia de aquello que no se tiene. Para ello, haremos un pequeño recorrido por las dos líneas de pensamiento que han sido fundantes en la reflexión y el estudio del deseo, y que han instituido a nuestro juicio unas maneras de desear. En este sentido, abordaremos inicialmente al deseo desde su positividad; es decir, entendido como potencia productiva, abordando autores como Spinoza, Nietszche, Deleuze, Guattari y Foucault. En segundo lugar, haremos un breve recorrido por la línea de pensamiento que asume el deseo como carencia fundamentalmente en autores como Freud, Sartre y Lacan. Posteriormente, se presentan las categorías emergentes y una perspectiva de comprensión de ellas.

\subsubsection{El deseo como potencia}

¿Qué implica entonces el deseo como potencia en el contexto de nuestra investigación? En primer lugar, ubicar el deseo en una corriente de pensamiento que apostó por visibilizarlo desde su positividad y, en segundo lugar, acentuar la relación entre el deseo de lo indeterminado y la vivencia del límite como posibilidad. Para ello, nos ubicaremos inicialmente en el pensamiento de Spinoza $(1677,1985)$ y de su reconocimiento del deseo como uno de los tres afectos primitivos. ${ }^{4}$ Para este autor, el deseo es: «la esencia misma del hombre en cuanto es concebida como determinada a obrar algo por una afección cualquiera dada en ella» (Spinoza, 1985: 154), convirtiéndose en un horizonte ontológico, en el cual las pasiones no son pasividad sino formas de actuación. Su planteamiento se opone al de Aristóteles que orientó el deseo hacia el bien, hacia lo que nos parece bueno. Por el contrario, para Spinoza (1985: 135):

Nada deseamos porque juzgamos que es bueno, sino por el contrario, llamamos bueno lo que deseamos; y, por consiguiente, llamamos malo, lo que aborrecemos; por lo tanto cada cual juzga o estima, según su afecto, lo que es bueno, lo que es malo, lo que es mejor, lo que es peor y, en fin, lo que es óptimo o lo que es pésimo.

Así, pues, el deseo es: «el apetito con conciencia de él» y el apetito está relacionado con el esfuerzo (conatus) ${ }^{5}$ cuando se refiere al alma y al cuerpo y cuando se refiere al

Los otros dos serían la alegría y la tristeza

5 Por conatus, en la perspectiva spinoziana, se entiende ese esfuerzo de cada cosa por perseverar en su ser: «Ninguna cosa puede ser destruida sino por causa externa» (Spinoza, 1985:110); y «cuanto más se esfuerza cada cual en buscar lo que le es útil, esto es, conservar su ser, y puede conservarlo, tanto más dotado de virtud está; y por el contrario, en cuanto cada cual descuida conservar lo que es útil, esto es, su ser, es impotente» (Spinoza, 1985:190). Esta perspectiva es criticada por Nietzsche, cuando plantea que: «la 
alma sola Spinoza lo denominaría voluntad. Entonces, el deseo desde esta perspectiva es el esfuerzo y la voluntad en cuanto obramos. ${ }^{6}$

Nietszche retoma el planteamiento de potencia de Spinoza, pero no en la perspectiva del conatus, sino en la línea de un deseo con voluntad afirmativa que hace potentes y poderosos a aquellos que buscan nuevas posibilidades de vida y nuevas formas de interpretación; aquellos que se abren a lo posible y a lo indeterminado, a la transformación, relacionando vida, potencia, gozo y eternidad: « $i O h$, alma mía, te he devuelto la libertad sobre lo creado y lo por crear; ¿y quién conoce, como tú, la voluptuosidad de lo por venir?» (Nietszche, 1998: 240). Porque la vida es voluntad de potencia y los hombres superiores son aquellos que: «queréis crear un mundo ante el cual podáis postraros; tal es vuestra esperanza y ebriedad última» (Nietszche, 1998: 124). ${ }^{7}$

En esta misma línea de pensamiento se ubica el deseo desde la perspectiva de Deleuze y Guattari (2004: 159). Para ellos, el deseo es un proceso de producción donde el cuerpo sin órganos ${ }^{8}$ es su campo de inmanencia: «sin referencia a ninguna instancia externa, carencia que vendría a socavarlo, placer que vendría a colmarlo». Así el deseo posee un gozo inmanente, intensidades de placer que hacen que el deseo se llene a sí mismo. ${ }^{9}$

vida misma es voluntad de potencia (poderío). La conservación de sí mismo no es más que una de las consecuencias indirectas más frecuentes. En resumen: aquí, como en otra parte, guardaos los principios teológicos superfluos, tales como el instinto de conservación (el esfuerzo de perseverar en el ser, que se debe a la inconsecuencia de Spinoza)» (Nietzsche, 1947: 39).

6 En este sentido, el deseo se relacionaría con todos los esfuerzos, impulsos, apetitos y voliciones del hombre; y es en esa relación con el obrar y con el esfuerzo donde precisamente se afirma la potencia, porque es potencia de obrar o fuerza de existir que se aumenta o disminuye, se favorece o se reprime, en su relación con la alegría y con la tristeza; o sea, con los afectos y las pasiones. El deseo como potencia es fundamental para comprender cómo las y los jóvenes se enfrentan al límite y en el esfuerzo por lograr aquello que no es posible pero que imaginan. Porque la imaginación aumenta o favorece la potencia de obrar de nuestro cuerpo, por consiguiente, se aumenta o favorece la potencia de pensar del alma; y de forma recíproca, el alma se esfuerza cuanto puede, por imaginar esas cosas (Spinoza, 1985).

7 Son aquellos que se han enfrentado a la adversidad, a los límites; los intrépidos que vivencian el gozo que sólo quiere eternidad: «Pues todo gozo se quiere así mismo; ¡de ahí que quiere también la pena! ¡Oh, dicha! ¡Oh, dolor! ¡Oh, sucumbe, corazón! Hombres superiores, aprended que el gozo quiere eternidad; -que el gozo quiere la eternidad de todas las cosas; que iquiere eternidad profunda, oh, tan profunda!» (Nietzsche, 1998: 346). Pero aclarando que: «sólo puede ser intrépido quien conoce el miedo, pero lo supera; quien ve el abismo, pero con orgullo» (Nietszche, 1998: 308).

8 El cuerpo sin organos $(\mathrm{CsO})$ es un concepto que estos dos autores retomaron de Artaud, no en oposición a los órganos, sino a la noción de "organismo", o sea a la organización orgánica de los órganos. Un cuerpo con carácter fluido y resbaladizo que: «está hecho de tal forma que sólo puede ser ocupado, poblado por intensidades. Sólo las intensidades pasan y circulan» (Deleuze y Guattari, 2004: 158).

9 Por tanto es un deseo liberado de la carencia (de su ley negativa), de la regla externa del placer y del ideal trascendente del fantasma. Entonces: «el sacerdote ha dicho el deseo es carencia [...] realizaba así el primer sacrificio llamado castración [...] ha relacionado el deseo con el placer [...] realizaba así el segundo sacrificio llamado masturbación [...] Exclamó el goce es imposible, pero el imposible goce está inscrito en el deseo [...] realizaba así el tercer sacrificio el fantasma» (Deleuze y Guattari, 2004: 160). El deseo como potencia productiva se asume como multiplicidad pura, buscando superar la relación predicativa de lo uno y de lo múltiple, en este sentido: «El problema ya no es el de lo Uno y de lo Múltiple, sino el de la multiplicidad de fusión que desborda efectivamente cualquier oposición entre lo uno y lo múltiple» (Deleuze y Guattari, 2004: 159). El deseo es un continuum de intensidades, flujos, fragmentos de inmanencia y formas de voluntad de vivir, de crear, de amar. No hay universales, ni una esencia bestial del deseo, éste es siempre el modo de producción y construcción de algo (Guattari y Rolnik, 2005). 
Foucault inicialmente partiría de la pregunta: ¿De qué manera se articulan poder y deseo?, rechazando la hipótesis represiva y el proyecto de puesta en discurso del sexo, heredado de la vida ascética y monástica, y de la pastoral cristiana, lo que permitiría: «producir efectos sobre él, efectos de dominio y desapego, pero también de reconversión espiritual [...] efectos múltiples de desplazamiento, de intensificación, de reorientación y de modificación sobre el deseo mismo» (Foucault, 1984: 29). ${ }^{10}$

\subsubsection{El deseo como carencia}

El deseo como carencia se ubica en una perspectiva que lo asume desde su raíz latina desiderium como: «alejamiento de Dios, como caída del cielo y de los astros (sidera), desastre [...] cesar de contemplar los astros» (Domoulié, 2005: 83). Corresponde además a la línea del pensamiento platónico, ${ }^{11}$ que vio al deseo de forma negativa y lo relacionó con la carencia, la muerte y la falta; así mismo, con la perspectiva que introdujo el cristianismo de eliminación del deseo y la asociación con la mujer, lo malo y hasta lo demoníaco.

En esta línea se ubica también el psicoanálisis, al vincular al deseo a la castración, a la pulsión de muerte y a la neurosis, pues:

"No fue sin razón que Freud rescató el término "Libido" para designar la potencia del deseo. Numerosas nociones psicoanalíticas, como por ejemplo pulsión de muerte, compulsión de repetición, inquietante extrañeza, poseen connotaciones diabólicas. El deseo está en falta, pues está en carencia, él es falta, carencia” (Domoulié, 2005: 83).

La perspectiva del deseo como carencia introduce la presencia de objetos de deseo y la satisfacción de necesidades, el apego al fantasma, así como la imagen ideal de lo amado que va convirtiendo la pulsión en destino. En este sentido, la realización del deseo no es la posesión de un objeto real, es la reproducción alucinatoria de una percepción

10 Según este autor se trata de reconocer que la ley es constitutiva del deseo y de la carencia que la instaura. Por tanto, el poder está donde está el deseo y no es posible partir a la búsqueda del deseo al margen del poder. Esta forma de mirar cambió en el II tomo de la Historia de la sexualidad. El uso de placeres. Para Foucault (1986: 208) existe una relación dinámica, una fuerza que une entre sí actos, placeres y deseos, lo que constituye el foco de la experiencia ética de la aphrodisia. Su propuesta no es una ontología de la carencia: «se trata más bien de la dinámica que los une a los tres de manera circular (el deseo que lleva al acto, el acto que esta ligado al placer, y el placer que suscita el deseo)». Así, pues, lo ético no se plantea en relación con: ¿qué deseos, qué actos, qué placeres?, sino ¿con qué fuerza nos dejamos llevar por los placeres y los deseos? A lo cual Foucault dedicó el III tomo de la Historia de la Sexualidad. La inquietud de sí (Foucault, 1987). La reflexión fue colocada en términos de las preguntas: ¿en qué medida se es capaz de gobernarse a sí mismo? ¿qué poder se ejerce sobre sí mismo que pueda mediar (la fuerza y la intensidad) en la relación con el objeto de placer, con los demás y con el mundo? Este tema en que se relaciona la inquietud de sí con el deseo lo considero de gran importancia; Foucault lo abordó desde la cultura griega, desde el "cultivo de sî", desde el "cuidar de uno mismo", ocupándose de uno mismo (heautou epimeleisthai) y aquí se abordará desde la práctica como una forma de cuidado de sí.

11 "El objeto de deseo no es lo agradable" (he gar epithymia tou hedêus estin). En este sentido Foucault (1986: 42) plantea que Platón reitera con frecuencia que: «no podría haber deseo sin privación, sin carencia de la cosa deseada, y sin mezcla por consiguiente de cierto sufrimiento; pero el apetito, explica en el Filebo, sólo puede provocarse con la representación, la imagen o el recuerdo de lo que da placer; de ahí concluye que no podría haber deseo más que en el alma, ya que si el cuerpo es alcanzado por la carencia, es el alma y sólo el alma la que puede por el recuerdo hacer presente lo que se desea y así suscitar la epithymia». 
cuya imagen mnésica es de nuevo invertida. Freud (2005a: 113) plantea que del «estado de deseo se sigue directamente una atracción hacia el objeto de deseo, respectivamente su huella mnémica». Para este autor (2005a: 115): «el estado de deseo inviste de nuevo el objeto-recuerdo y entonces decreta la descarga, no obstante que la satisfacción por fuerza faltara, porque el objeto no tiene presencia real sino sólo en una representación-fantasía». Así, entonces, el deseo se ubicará en el mundo como representación, sin relación directa con lo real o con las pulsiones, ya que estas relaciones siempre son representaciones de afectos (representaciones de representaciones). ${ }^{12}$

El deseo como carencia se nutre no sólo del pensamiento platónico, del cristianismo y del psicoanálisis, en él también podría ubicarse el pensamiento hegeliano donde el deseo es el motor de la historia pero en relación con la carencia y la muerte. Al igual que el deseo en la versión de Sartre $(1943,1993)$, en esa relación que establece entre libertad-carencia. ${ }^{13}$

Lacan (1997) asume que el deseo del hombre es el deseo del Otro, pero de ese Otro que es carencia radical, ya que el cuerpo del Otro (objeto a), sólo promueve la infinitud, porque el objeto a es un objeto sustituto o un objeto fantasma. Así cuando «Aquiles ha dado su paso, terminando su lance con Briseis, ésta, como la tortuga, avanza un poco, porque es no toda, no toda suya. Todavía queda. Y es necesario que Aquiles dé el segundo paso, y así sucesivamente» (Lacan, 1997: 15), lo que implica que nunca llegará al límite, convirtiendo en objeto trascendental esta carencia radical. ${ }^{14}$

12 Freud (2005b: 44) afirmó en La interpretación de los sueños que: «el cumplimiento de deseos es el sentido de todo sueño». Para ello planteó la necesidad de interpretar el contenido latente existente en el contenido manifiesto, de tal forma que hasta los sueños penosos y los de angustia se revelerán como cumplimiento de deseos. El deseo se convierte en una especie de historia cifrada que debe develarse mediante la interpretación psicoanalítica, en un discurso que va trazando su camino en sueños, lapsos y síntomas. La imposible satisfacción del deseo en el presente, su naturaleza alucinatoria es sustituida por Freud por una satisfacción regresiva de la libido, entonces el deseo, se vincula a la representación, al inconsciente, a la imagen recuerdo, a la primera infancia, a la familia, a sueños, lapsos, síntomas. De esta forma: «el deseo se desdobla entre su fuente originaria inconsciente: los trazos primitivos para siempre incognoscibles, más de donde emana señales, es la proyección fantasmática donde escribe el escenario de su realización" (Domoulié, 2005: 120).

13 Para este autor las tentativas de búsqueda de libertad se dan en relación al Otro, que convierto en objeto, y del cual sólo me puedo apropiar a través de su cuerpo. El deseo para Sartre está relacionado con el instinto sexual y con las estructuras psíquicas relacionadas con él. Pero se desea a un ser humano: «en tanto él está y yo estoy en situación en el mundo, y en tanto que él es Otro para mí y yo soy Otro para él» (Sartre, 1993: 409). Sartre opta por un camino trascendente (objeto trascendente) para el deseo y considera que cualquier opción subjetivista e inmanente del deseo esta destinada al fracaso, porque el deseo no es deseo de posesión física o de objeto deseado, ya que lo deseable es el deseo mismo. Igualmente, introduce la pregunta ¿Quién desea?, lo cual le permite plantear que el deseo es un modo singular de la subjetividad de quien desea, una turbación desde la cual se busca tomar, apropiarse y someter al Otro, no sólo como Otro-objeto sino como trascendencia encarnada. Esta forma de mirar el deseo fue posteriormente retomada por Lacan y se convirtió en el fundamento de una de las perspectivas que asumiría el psicoanálisis.

14 Para este autor, el sujeto es sujeto del deseo y el significante su forma de representación, de ahí el énfasis puesto en el lenguaje. Sujeto escindido por la carencia del objeto perdido, en donde el deseo es la diferencia entre satisfacción, necesidad y el infinito de la demanda; al fin y al cabo siempre está buscando su completud, al haber sido divido por la carencia de la Cosa (la Cosa asumido por Lacan, 1997, como el Otro absoluto del sujeto que trata otra vez de encontrar), pero al mismo tiempo nunca quiere que su demanda sea satisfecha. Es por eso que en la teoría lacaniana del deseo la carencia es elevada a categoría reguladora. 
El deseo como carencia ha sido una de las perspectivas más potentes y más fuertemente instituidas. Incrementar la insatisfacción del deseo y crear nuevas necesidades, anhelos y satisfactores, es una de las tareas fundamentales desde la cual el consumo asume el deseo. A su vez, el deseo como carencia es uno de los discursos y de las prácticas promovido por la industria cultural y es desde esta perspectiva donde se configuran y se instituyen significaciones imaginarias que relacionan deseo con objetos de deseo.

\subsection{LA APROXIMACIÓN EMPÍRICA. ENTRAMADO DE POTENCIA Y CARENCIA ${ }^{15}$}

\subsubsection{Deseo y límite. ${ }^{16}$ Entramado de "evolución” y "superación"17}

Yo relaciono el deseo más con superación, pero ese deseo bien enfocado [...] cuando uno desea es para hacer algo positivo para la vida de uno (I:06/Gr:Dm/Tec:Ep/R: 03/G:M)

La experiencia del límite hace que en las prácticas se vayan configurando significaciones imaginarias, que podríamos ubicar en una perspectiva del deseo como potencia; sólo que éstas se dan en medio de significaciones imaginarias del deseo como carencia que están presentes en sus prácticas, en sus grupos y en los contextos sociales que hacen parte de su cotidianidad. En tal sentido, un joven practicante de skate boarding nos plantea: «Deseo traspasar fronteras, no tener un límite en la vida, llegar a muchas partes y a muchos lugares y si es posible poder conquistar el mundo» (I:04/G:Skb/ Tec:D/R:1/G:M). Avanzar a otras dimensiones que son consideradas como ideales y que están mixturando la superación de los límites técnicos, de estilo y fluidez, de transformación de la realidad vivida; pero también en la posibilidad de consecución de ciertos bienes materiales como automóvil, viajes. Lo que puede comprenderse en el contexto de sus prácticas, pero también en su origen de clase, donde los pobres quieren tener éxito en un país de esperanzas y expectativas.

Lo particular de esta mixtura de significaciones es que se da al interior de unas prácticas que tienen en común no sólo la experiencia del límite, sino también el gozo, el disfrute, la libertad y la solidaridad. Y es precisamente esa la condición que hace que su esfuerzo se ponga en obra; por esta razón, Spinoza (1985: 130) planteaba que: «La cosa que amamos con preferencia a los demás, nos esforzamos cuanto podemos, en imaginarla», en afectarla de alegría, esforzándonos por conseguirla. Aquello que se hace por gusto y se ama pone la idea del esfuerzo; o sea, del deseo como potencia. Esto moviliza a obrar alcanzando metas pequeñas para pensar luego en metas grandes, en

15 Existen dos conceptos claves en la propuesta de configuración de Elias (1999), el primero de ellos es el concepto de entramado. Este concepto fue utilizado para referirse a esa gama de interdependencias que está presente en las relaciones humanas, relievando el carácter procesual de toda relación entre personas. Para nuestro caso, el concepto de entramado será usado de forma más amplia y no se limitará a las interdependencias humanas, la idea es que su uso pueda ampliarse para hacer referencia a los entrecruzamientos de las significaciones imaginarias, de las mixturas y de las hibridaciones entre ellas (Hurtado, 2008: 97).

16 El límite aparece como un elemento presente en estas prácticas de subjetivación y en las significaciones imaginarias de deseo de los jóvenes. Afrontarlo no implica necesariamente superarlo, el límite puede ser obstáculo insalvable, frustración, miedo y dolor. Esa doble condición que está presente en la experiencia permanente de desafiarse ante él, podría ser abordado como experiencia liminal; o sea como una experiencia que implica la ubicación en un lugar que no se sitúa en ningún lugar pero que es un lugar en sí mismo. Términos utilizados por los jóvenes y que han sido extraídos de algunos relatos. 
alcanzar una y ponerse inmediatamente otras y también en lo bueno y placentero que es ir cumpliendo las metas propuestas. Se hace evidente una temporalidad distinta a la de la cultura parental y sus metas de largo plazo, donde el futuro se había convertido en la significación temporal central. Son metas de corto plazo más que de grandes proyectos para toda la vida y que están vinculados con la cotidianidad de la práctica y con la incertidumbre del mundo contemporáneo.

La relación entre deseo y límite pone en evidencia una búsqueda de placer y satisfacción en otra temporalidad: en "el aquí y el ahora", en el presente, pero es un presente para el cual es necesario estar preparado. El "aquí y el ahora", contrariamente a lo que podría pensarse, no es la significación de la incertidumbre, sino que ante la incertidumbre del futuro sólo queda la certeza de lo que soy (ahora) y de lo que tengo; lo que puedo tener y alcanzar se enuncia en tanto tengo control y dominio sobre esto. En tal sentido, el deseo se relaciona con hacer reales los objetivos propuestos, con hacer lo que les gusta y prepararse para realizar su práctica. La preparación es un elemento de enorme importancia cuando de desafiarse al límite se trata. Esto implica prepararse y practicar hasta el máximo de sus posibilidades, sacar tiempo para la práctica, verraquera y ganas.

Un deseo que se moviliza, que hace tránsito hacia nuevos deseos y nuevas experiencias como lo expresara Spinoza y que en nada diferiría de ciertas características del deseo y sus significaciones relacionadas con la carencia. ${ }^{18}$ Pero este desear otras cosas, se da desde una perspectiva del esfuerzo y no de la carencia radical, por la vía de que a mayor esfuerzo, a mayor dificultad para alcanzar la meta, mayor placer. Es la búsqueda por mejorar, por hacer cosas más complicadas que no necesariamente están en la dinámica de los otros, sino que implican retos consigo mismos, esfuerzo y preparación. Esto puede implicar a veces hacerse daño. La práctica se convierte en: «un vicio que no se podía dejar así se hiciera daño, por eso el skate era como un vicio dañino, porqué uno se cae y se golpea, hasta se fractura, pero eso no le importaba»(G:Skb/Tec:Dc/R:63/G:M).

La "evolución" que plantean los jóvenes no sólo se restringe a un mejoramiento de la técnica, sino a las posibilidades de abrir la mente a otras realidades distintas a las que se tienen y otras posibilidades de ver el mundo. Pero también es colocada en términos de reconocimiento tanto a nivel local como nacional: «salir adelante con la banda, que nos conozcan más» (I:05/Gr:Dm/Tec:Ep/R:27/G:M). Se trata de hacer rutina aquella sensación que se siente cuando alcanzan un nuevo nivel; es una creencia de que lo propuesto lo pueden hacer. Forma de lucirse, de diferenciarse y, a veces, hasta de causar miedo a la gente. Esta "evolución" implica madurar, cambiar la manera de ver el mundo, incluye aprendizajes de todo tipo, que pueden ser considerados desde fuera buenos o malos, lo que a nivel grupal les genera respeto. Implica aprendizajes que no necesariamente les brinda el grupo, éstos se pueden lograr a través de videos y otros recursos, donde la competencia se considera como un espacio de aprendizaje. Búsquedas individuales que se comparten y se de-muestran, que permiten poner en evidencia cómo han mejorado, cómo han avanzado en su proceso y retar a los otros a que emprendan su propio camino.

18 Para Spinoza: «Acontece frecuentemente que mientras disfrutamos de la cosa que apetecíamos, el cuerpo adquiere por este disfrute una nueva disposición por la cual es determinado de otra manera y se excitan en él otras imágenes de las cosas, y el alma comienza al mismo tiempo a imaginar otras cosas y a desear otras cosas» (1985: 154). 
Entonces, el deseo en la relación con el límite se mueve en la dirección del esfuerzo para hacer posible aquello que se considera imposible y alcanzable lo inalcanzable. A pesar de que en esta categoría se han utilizado los términos de "evolución" y "superación" que estaban presentes en los relatos; es necesario aclarar que, desde su perspectiva, el deseo se plantea como el tránsito hacia el límite, como un "pasar caminos" que envuelve esfuerzo y capacidad de reconocerse; transitar por etapas que no necesariamente son lineales, ni ascendentes, que no significan "crecer o desarrollarse", sino la vivencia de estados de plenitud o de conflicto, ya que consideran que "estar quietos es estar muertos". Pero este transitar con esfuerzo también es la búsqueda por un espacio en el mundo hecho a su medida y que no necesariamente coincide con las expectativas de la familia y la sociedad.

\title{
2.2.2. Deseo y querer. Entramado de tener y satisfacción
}

\begin{abstract}
El deseo siempre está ligado al querer, siempre ... yo quiero tal cosa, yo quiero a ..., quiero tener esto, quiero ir a ..., el placer es cuando estás peleando por él, cuando vas por el recorrido, y la satisfacción es llegar a ese punto, quisiste algo y ya llegaste a él, pero entonces es una llegada inconclusa, llegás a un punto y querés ir al otro. Entonces la satisfacción es lo que te lo permite ;si pudo, hágale! pero hágalo con gusto y las va llevando así, querés algo, te gusta hacerlo y vas pa allá y cada vez que llegas a ese punto, vas andando, eso es lo que te permite seguir (I:07/Gr:Me/Tec:Ep/R:77/G:M).
\end{abstract}

El anterior relato nos muestra la relación que establecen los jóvenes entre deseo y querer. El querer se vincula hacia una persona, un objeto o un lugar. De esta misma forma, se establece una relación entre deseo, placer y satisfacción, en la medida en que el placer está ligado a la búsqueda de aquello que se quiere; el placer por hacer lo necesario para obtener lo deseado y, por último, el vínculo con la satisfacción como aquello que se obtiene cuando se sacia el deseo, cuando se obtiene lo que se quiere. Igualmente, se resalta lo inconcluso de este llegar, la búsqueda de un nuevo lugar y la motivación para esta búsqueda obtenida luego de haber alcanzado lo anteriormente deseado. Aquí podríamos hacer una reflexión sobre el tipo de significaciones que vinculan deseo con querer: deseo aquello que no tengo y eso implica estar siempre deseando algo nuevo, algo que no concluye jamás.

Existen ya referentes investigativos que vinculan el deseo con el tener, como, por ejemplo, la investigación realizada por Cortés y reseñada por Serrano (2004) en jóvenes urbanos de estrato alto de Bogotá. «El gusto y el tener son entonces dinámicas que marcan la relación que estos jóvenes establecen con el deseo, con las ideas de lo que son y/o quieren ser y por eso son los que permiten una buena vida sin problemas y casi feliz» (Serrano, 2004: 87). El tener entra en el terreno de lo previsible en la medida en que se concreta en objetos de consumo (ropa de marca, carros, viajes entre otros) y del dinero como el camino para alcanzar esos objetos.

\subsubsection{Deseo, dinero, estudio y prácticas}

La relación deseo, dinero, estudio y prácticas configura un entramado desde el cual el estudio es el camino para acceder al dinero, lo que les permite satisfacer el deseo. El deseo en esta relación es carencia o carencias que se sufren en las realidades que viven y en sus prácticas. De esta manera, un joven aficionado al skate boarding plantea que: 
«Lo real es lo que da pie al deseo, a lo no real, digámoslo así, porque para mí es eso, lo que uno desea es algo que aspira, que quiere, pero que no tiene, entonces al no tenerse es algo no real» (I:03/G:Skb/Tec:D/R:32/G:M).

Esa relación es expresada en estos términos: a mayor conocimiento, mejores empleos, mejores ingresos y mejores posibilidades de desarrollo en la práctica. En esa perspectiva se estudia o se estudió, para mejorar su estilo de vida, progresar y lograr financiarse sus prácticas. En la relación del deseo y el querer, el dinero está planteado como algo necesario más no prioritario, debido a que las prácticas les permiten otro tipo de realizaciones personales, como poder hacer lo que quieren con toda libertad. Aquí aparece otro elemento muy importante como es el del "gusto" relacionado con aquello que se quiere; o sea, aquello que moviliza a tener y hacer ciertas cosas, configurando una tríada gustoquerer-tener. El gusto aparece afín con la práctica y con ciertos objetos que son propios de ella y de otros que no; que se hacen deseables desde la influencias de otros espacios.

En el anterior relato se muestra como el gusto por la práctica desplaza la búsqueda de dinero como prioridad. El dinero, dice un estudiante del movimiento estudiantil, es «algo necesario [...] uno intenta no depender de él, intenta necesitarlo lo menos posible» (I:08/Gr:Me/Tec:Ep/R:32/G:F). Es como una recompensa por el trabajo con lo cual se compran cosas materiales, cosas que aparecen como sueños y cambian día a día. Pero igualmente como una limitante para acceder a ellas.

Los jóvenes consideran que el dinero no sólo les mejora su calidad de vida, sino que además les ofrece la posibilidad de ser independientes y tener mayor libertad y autonomía. El dinero les permite tener mejores implementos, satisfacer sus necesidades básicas, viajar, comer o divertirse. El dinero es un medio para: «tener, poseer y gozar también, siempre, yo quiero una comida que me guste y me la voy a gozar comiéndomela»(I:07/ Gr:Me/Tec:Ep/R:79/G:M). Ellos consideran que si no tienen dinero no pueden practicar, ya que son costosos los implementos, los viajes, la música y otros elementos propios de las prácticas. Además, el dinero garantiza contar con el tiempo disponible para practicar. Quien tiene dinero no tiene que preocuparse resolviendo el asunto de conseguirlo, lo que les permite ser dueños de su tiempo. Así: «Vos teniendo dinero, vos sos dueño de tu tiempo, podes patinar cuando queras» (I:03/G:Skb/Tec:D/R:23/G:M). Pero también se resalta que al interior de los grupos se puede dar otro tipo de prácticas como el trueque de objetos, que por supuesto no suplen la necesidad del dinero, ya que sus necesidades básicas se pagan con éste.

La idea de seguir estudiando y seguir en la práctica o buscar otras ciudades donde sean posibles nuevas alternativas relacionadas con lo que se hace, ya que son conscientes de no poder vivir de su práctica cultural en Popayán. Buscan terminar los estudios y tener un sustento económico para sobrevivir. Los jóvenes ven en el estudio la posibilidad de brindarle bienestar a la familia, progresar, de saber muchas cosas, facilitar su estilo de vida y ayudarse económicamente en relación con la práctica cultural que han asumido: «Estudio porque estoy buscando un lucro. ¿Por qué un lucro? Porque uno estudia, es para eso, para facilitar su estilo de vida» (I:03/G:Skb/Tec:Ep/R:42/G:M). Este elemento es muy importante teniendo en cuenta que la mayoría de nuestros informantes gozan o gozaron de moratoria social, además de ser en sus familias los primeros que asistieron a la universidad.

El trabajo se considera como el camino para obtener lo que se necesita o como la manera de rebuscarse para comprar las cosas, proponerse tener algún bien material 
y obtenerlo. El estudio y el dinero son considerados por los jóvenes importantes y de gran relación con sus prácticas. El dinero es lo que les permite adquirir los elementos necesarios para ellas y están conscientes de su inmersión en el mundo del consumo. El dinero sigue siendo un mediador fundamental entre deseo y satisfacción. A pesar de no considerar el dinero un elemento prioritario, saben que es clave para el desarrollo de sus vidas $\mathrm{y}$, a pesar de haber intentado buscar alternativas de intercambio de objetos y alimentos son conscientes que en el contexto donde viven no pueden prescindir de éste.

Estas significaciones, a nuestro juicio, tienen estrecha relación con la condición de moratoria social que disfrutan en calidad de estudiantes universitarios; con las significaciones que se instituyen desde el mundo adulto y que están fuertemente encarnadas en la escuela. De todas formas, estos jóvenes hacen parte, en su gran mayoría, de un grupo privilegiado que ha podido ingresar a la universidad, que ha podido ampliar su moratoria y que de otro modo quizás no disfrutarían de ese capital temporal. No necesariamente su ingreso al mundo del trabajo está garantizado, pero esa sigue siendo la quimera en la cual afincan su proyecto de vida y de la cual esperan, por la vía de la venta de su trabajo, obtener dinero y la garantía de inclusión al mundo del consumo.

Uno de los aspectos que valdría la pena mencionar es que contrariamente a lo planteado por Bauman (2004, 2003), el deseo no ha logrado aquí liberarse de la necesidad, sus vínculos con el dinero siguen estando relacionados con la satisfacción de necesidades básicas y el mejoramiento de su calidad de vida. Ellos están inmersos en la sociedad de consumo pero resolviendo día a día asuntos que hacen parte de las lógicas de la sociedad de productores por la vía del estudio-trabajo, por la vía de la supervivencia biológica y social. Los jóvenes también tienen claro, en este contexto, que es el dinero lo que les permite libertad e independencia y que han sido los recursos propios o aportados por sus padres lo que ha posibilitado llevar a cabo su práctica, lo que les ha permitido configurar espacios donde el dinero, precisamente no ocupa un papel central y al mismo tiempo ser dueños de su tiempo.

Ser dueños de su tiempo implica haber ampliado el espectro de posibilidades de los cuales otros jóvenes de su misma ciudad no pueden disfrutar, tanto por no encontrarse en moratoria social o por no poseer los recursos económicos necesarios que se los permita. Significa considerar que se dispone de un mayor capital temporal, entendido como la posibilidad de «gozar de un plus de tiempo, un excedente temporal, que es considerablemente mayor que el de las generaciones mayores co-existentes» (Margullis y Urresti, 1998: 10). ${ }^{19}$ Sus prácticas abren el abanico de posibilidades de realización personal y de perfomances vitales, pero no pueden liberarse como lo plantean estos autores de la clase social, porque, como vimos anteriormente en la relación con el dinero, el capital temporal depende de ella.

\subsubsection{Satisfacción y reconocimiento}

Los jóvenes identifican que pueden haber dos tipos de satisfacción: la primera está relacionada con la necesidad que se suple y, en este sentido, más vinculada con la relación

9 Esa experiencia subjetiva no cambia: «aunque la vida puede perderse en el momento siguiente, aunque las expectativas de vida se reduzcan objetivamente, aunque aumenten los riesgos sociales de muerte violenta, como guerras, represión política, inseguridad urbana, y otros fenómenos que generalmente encuentran entre los jóvenes sus principales victimas» (Margullis y Urresti, 1998: 10). 
querer-tener; y la segunda, ligada más a las prácticas y, por lo tanto, se relaciona más con el reconocimiento.

En la satisfacción que está vinculada con la necesidad, con aquello que se suple, aparecen las necesidades básicas y el deseo de lo que se quiere, en términos de aquello que se necesita. La necesidad se satisface y el placer se da en el momento en que empieza a ser suplida la necesidad. Pero la satisfacción es considerada momentánea, en tanto vendrán nuevas necesidades. También, y como en el caso del dinero, la satisfacción relacionada con el tener no es prioritaria, pero si se tiene no se niegan la posibilidad de disfrutarla.

El otro tipo de satisfacción se vincula con lo que se está haciendo ahora, sumado con lo que ya se logró, con saber que lo que se hace, se hace con gusto. Cada cosa brinda una satisfacción diferente y es el premio a tantas horas de esfuerzo. Satisfacción relacionada con aprendizaje, práctica, gusto, viajes, pasarla bien y compartir con los amigos; con el reconocimiento que se tiene por aquello que se hace, y como una recompensa por el esfuerzo. La satisfacción relacionada con aquello deseado y que se alcanza, como sentirse contento y feliz por el logro, con la superación pero también con las derrotas. « $L a$ satisfacción de saber que todo lo hacemos porque nos gusta, porque le tenemos amor a las cosas, porque nos inspira »(I:01/Gr:Cp/Tec:Ep/R:67/G:F).

Este tipo de satisfacción que se vincula con la práctica cultural está relacionada con procesos de desarrollo personal y logros propios, con el gozo de hacer lo que les gusta y de luchar y ser recompensado por su esfuerzo. Ello es, a mi juicio, lo que Spinoza denominó satisfacción de sí mismo, lo que para él era «una alegría nacida de que el hombre se considera a sí mismo y considera su propia potencia de obrar» (Spinoza, 1985: 162). La alegría de hacer su práctica por gusto, potencia de obrar que no es otra cosa que el deseo de alcanzar los logros por ellos propuestos e igualmente luchar, perseverar, ser derrotados, pero igualmente «una alegría acompañada por la idea de sí como causa» (Spinoza: 1985: 162) que los moviliza hacia sus propios límites y al límite como experiencia.

Obtener reconocimiento y haberlo logrado mediante la práctica es lo tangible de aquello que se ha vivido. Conciertos, participaciones en torneos y viajes, son algunas de las cosas que se enuncian como aquello que se ha realizado. De esta forma, se plantea que se obtiene «Reconocimiento por parte de la gente, de todo el que te toque, del que te confronte, o sea, tener un buen nombre ante el otro» (I:07/Gr:Me/Tec:Ep/R:72/G:M).

Esa satisfacción que se da en la mixtura entre el tener y el reconocimiento es una forma de escape de la racionalidad consumista, una forma de gratificarse en el desarrollo de prácticas de libertad. La satisfacción aparece como la emoción de tener y alcanzar lo deseado, como esa alegría que hace parte del correlato del tener y del hacer. Pero la satisfacción en su relación con la práctica cultural y sus logros tiene otro elemento: el reconocimiento, que es otra forma de recompensa por el esfuerzo y la dedicación; otra forma de satisfacción y, al mismo tiempo, una fuente de satisfacción.

Los dos entramados que he descrito en esta categoría "evolución - superación" y "tener - satisfacción" presentes en las relaciones deseo/limite - deseo/querer respectivamente, muestran la necesidad de volver sobre una comprensión del deseo como vivencia temporal. Si incluimos en nuestra forma de mirar el deseo como potencia y dejamos explicita su mixtura con el deseo como carencia, la relación no se restringe a la satisfacción, sino que se amplia también al reconocimiento, al placer de la vivencia y al desafío del límite como experiencia vital. 
Es así como se mixturan necesidades, satisfacción, placer; al igual que el hacer y el tener desde prácticas concretas en la cuales se vivencia temporalmente el deseo. Hablar de temporalidades es reconocer la configuración situada de múltiples tiempos sociales, pero igualmente el carácter temporal de la subjetividad (Leccardi, 2002). ${ }^{20}$ La temporalidad es un eje primordial de configuración de los sentidos sobre el mundo y la realidad. Es una categoría recurrente en los trabajos sobre jóvenes realizados desde diversas perspectivas, pues, a juicio de Feixa (2000: 89), «no sólo construye socialmente lo juvenil; sino también la juventud construye socialmente el tiempo en la medida en que modela, readapta y proyecta nuevas modalidades de vivencia temporal».

Finalmente, el deseo como vivencia temporal nos muestra cómo los entramados mixturan significaciones y cómo es necesario considerar que el carácter atópico de las significaciones tiene una estrecha relación con las mixturas temporales que los jóvenes experimentan en estas prácticas de subjetivación. Las referencias al presente y al futuro y sus respectivas mixturas, nos llevan a preguntarnos sobre qué sucedió con el pasado y sobre la poca importancia que los jóvenes le otorgan a éste, contrario a lo que sucede en el psicoanálisis. El pasado está presente como experiencia y la experiencia es valorada como sabiduría, pero las preguntas acerca de: ¿cómo el pasado me afecta? y ¿cómo esto me permite pensarme a futuro? pasaron a un segundo plano. Igualmente, lo que pone en evidencia, es que en el carácter evocativo del deseo, estaba implícito su vínculo con el futuro y esto sigue estando instituido, pero mixturado con el presente, debido al enorme acento que esta temporalidad tiene en estos momentos. Al fin y al cabo, pasado, presente y futuro son expresiones de «la facultad humana de sintetizar, así como, en este caso, de experimentar simultáneamente lo que no sucede al mismo tiempo» (Elias, 1997: 88).

\subsubsection{Significaciones imaginarias de deseo/placer.}

Entramado de hacer, erotismo y dolor.

En cualquier lado puede ocurrir eso del placer, en cualquier parte puede empezar ya a sentir ese placer, es como un proceso, siempre va estar ahí (I:06/Gr:Dm/Tec:Ep/R: 09/G:M).

La relación entre deseo y placer es una relación muy fuerte en las significaciones de las y los jóvenes; sin embargo, existen diferentes maneras en que ellos expresan esa relación, en términos de significaciones imaginarias. En este sentido, los jóvenes plantean que existen muchos tipos de placer.

No obstante, pese a la multiplicidad por ellos planteada en relación al placer, tendríamos tres aristas o juego de relaciones a ser consideradas. La primera, en su relación placer/hacer. La segunda, en la relación deseo/placer/erotismo; en este sentido, en su vínculo con el erotismo, la sexualidad y el cuerpo. La tercera, en la relación que los jóvenes hacen del deseo/placer/ dolor.

20 En los trabajos de Carmen Leccardi (2002) sobre la experiencia temporal en mujeres jóvenes, ella plantea que las construcciones biográficas son el resultado de la interrelación de tres ases temporales: el tiempo interior, que expresa la dimensión de la subjetividad y es inseparable del carácter corpóreo de la existencia humana, de su facticidad; el tiempo biográfico, a partir de la propuesta de Luckmann, como el proceso a través del cual el sujeto da significado al curso de su propia vida, sobre la base de los esquemas interpretativos sacados del stock de conocimientos socialmente disponibles en un determinado momento histórico; y por último, el tiempo histórico-social considerado como el producto de las actividades sociales históricamente determinadas. 


\subsubsection{Deseo/placer/hacer. El placer de hacer lo que uno quiere hacer}

El placer sería las cosas que uno hace y las cosas que uno ha construido. Todo lo que uno hace a diario que se ha programado hacer y cuando ya lo ves materializado, eso es lo que da placer (I:08/Gr:Me/Tec:Ep/R:28/G:F).

El placer se define en Spinoza (1985: 113) como: «afecto de la alegría referido simultáneamente al alma y al cuerpo» y la alegría para él es: «la transición del hombre de una menor a una mayor perfección» (Spinoza, 1985: 155). Esa alegría de la que nos habla Spinoza nos hace volver sobre la perspectiva del deseo como potencia, al vincular el performance que puedan lograr a través de sus prácticas culturales con el placer obtenido al alcanzar lo deseado.

Dentro de las significaciones que vinculan placer-hacer están las referidas a la posibilidad de soltarse corporalmente y disfrutar cada reto cumplido. Intensidad que entre más se experimenta, más se vivencia y se puede obtener de cualquier cosa. Una mezcla entre placer, vértigo y vacío. De hacer lo que se quiere y ser reconocido por ello, de ser validado en las cosas que se dicen y se hacen. Ellos encuentran: «placer en la música y todo lo que esté ligado a ella, hacer la música, escucharla, escribirla, todo eso» (I:05/ Gr:Dm/Tec:Ep/R:21/G:M). Pero, también, en las emociones que sienten, comparten y despiertan.

De otro lado, el placer también lo ubican en el intercambio, en la interacción, en el contacto, en reconocerse como una realidad que se construye de otras realidades, de la responsabilidad con los otros. Placeres que tienen que ver con la gente y que no necesariamente están relacionados con el dinero sino con la compañía.

Entonces, resulta ser un placer que se libera de la carencia, de la necesidad y que está puesto en relación con vivencias intensas de encuentro, de afectividad y de alegría. El placer en su relación con el hacer es la manifestación de un deseo que es potencia, que es esfuerzo; por tanto, es un campo de inmanencia que se vivencia en el momento mismo de la realización de la práctica o de la vivenciación del límite y de su experiencia. El placer así visto se convierte, al igual que la práctica, en una forma de volver sobre sí mismos, de volver sobre unas corporeidades que se exploran y se muestran y que se van poblando de un flujo de intensidades que ellos mismos buscan.

\subsubsection{Deseo/placer/erotismo. El erotismo le mueve a uno los sentidos}

El erotismo le mueve a uno los sentidos, el ojo, el oído, el tacto y el placer, cuando vos sentís placer sentís esas cosas hacia un cuerpo, desde el pelito más cortico de la cabeza hasta la punta del dedo chiquito del pie (I:07/Gr:Me/Tec:Ep/R:27/G:M).

Cuando planteamos la relación deseo/placer/ erotismo estamos dando cuenta de una de las significaciones imaginarias más fuertemente instituidas. El placer es vinculado al cuerpo, a lo erótico, a lo fisiológico, al sexo, a la pareja, al amor, a los orgasmos que se logran por diferentes medios y a esas emociones donde se pierde la noción de espacio y tiempo. Sin embargo, estas significaciones pueden estar relacionadas también con la práctica. Imágenes que ligan deseo y cuerpo y que se entrelazan en propósitos vaporosos que, a manera de flujos, emergen en el vacío de lo que es el deseo. De esta forma, el cuerpo es el generador del deseo, pero de igual forma el lugar donde se disfruta. En tal 
sentido, un joven de teatro nos describió la imagen de deseo que elaboró: «Esos rayones ahí tienen que ver con partes diferentes del cuerpo, por eso se entrelazan tanto, en línea hacia un sólo propósito que sería una cosa ya vaporosa, sobre un vacío que básicamente son los deseos y que salen, parten y se crean y se disfrutan a través del cuerpo» (I:10/ GrTe/Tec:D/R:01/G:M).

El placer en la relación con el erotismo es construcción de otro cuerpo, de un cuerpo que con otro se convierte en cuerpo nuevo, que surge a partir de la comunicación que establezco con el otro, de la capacidad de ese encuentro. El sexo es la máxima expresión del placer y el contacto con otra persona, con otro cuerpo, es lo que permite y de hecho hace la diferencia cuando de disfrutar el placer se trata.

Ellos plantean algunas referencias al amor en términos de comunicación, de correspondencias con la pareja que van mucho más allá de la parte física, de la parte orgánica. Las frecuencias y el encuentro es lo que posibilita entablar un diálogo que, a manera de ritmo, les permite conectarse y disfrutarlo. A esta relación deseo-amor que se pone en términos de comunicación con otro y que desborda lo corporal visto desde lo fisiológico y desde lo orgánico, es la relación desde la cual el placer se vincula con el erotismo, en la medida en que moviliza su vida interior, tal como lo planteara Bataille (2002); y no se restringe solamente a la actividad sexual, aunque la contiene, integrando otras dimensiones a partir del diálogo con otro con quien comparte el placer, con quien disfruta esa intensidad y esa fusión corpórea. Entonces, el placer aparece relacionado con formas redondas y al deseo que se disfruta a través del cuerpo, al cuerpo femenino y masculino, a espacios de intimidad, a objetos que se reconocen vinculados al encuentro sexual, texturas y formas que se consideran eróticas.

En la relación deseo/placer/erotismo se encuentra un fuerte acento en el deseo que se sacia en el Otro, como lo planteara Sartre (1993), con la posesión del Otro y con la vivencia de sensaciones corpóreas vinculadas al placer, a partir de la comunicación con otra corporeidad. El deseo, de esta manera, se condena a permanecer en la incompletud, pues ignora que no es más que deseo de ser Uno (Lacan, 1997). Sin embargo lo interesante, es que los jóvenes consideran que mediante el placer no sólo develan el cuerpo del Otro sino también su propio cuerpo.

Aquí el deseo es deseo de un cuerpo por otro cuerpo, y el ser que desea es la conciencia haciéndose cuerpo, pero el cuerpo del Otro es lo que me permite hacer consciencia del cuerpo propio; es ese construirse un cuerpo nuevo del que nos hablaron los jóvenes. En esa misma línea Sartre (1993: 415) afirmó: «la revelación de la carne ajena se hace por mi propia carne; en el deseo y en la caricia que lo expresa, me encarno para realizar la encarnación ajena; y la caricia, al realizar la encarnación del Otro, me descubre mi propia encarnación».

Es una relación que se afinca en una perspectiva del deseo como carencia; el cuerpo del Otro es falta, es el objeto que se pierde y desde el cual se intenta restablecer la completud y la continuidad. También es la posibilidad de gozo del placer; así, este placer está expresado en su relación con ciertos objetos y espacios que podrían considerarse externos al disfrute mismo del placer; al fin y al cabo, estos objetos responden a la interioridad que hago de ellos como objetos de deseo y sus vínculos con el encuentro erótico. 


\subsubsection{Deseo/placer/dolor. El dolor es placentero}

En la relación deseo/placer/dolor, el placer se obtiene a través del dolor; la experiencia del dolor, pues, se hace placentera. El placer no sólo es felicidad sino también tristeza y depresión. Tiene diferentes intensidades que dependen de la persona. Se puede obtener mediante la laceración, que es una forma de auto-producirse sensaciones. El dolor está ligado a la capacidad que tienen ellos mismos de crear el placer, de buscarlo, experimentarlo y vivirlo en la capacidad de crear y dejarse poblar por distintas intensidades de dolor, de intensidades que ellos no consideran alcanza el displacer. Una joven de teatro afirma que en la práctica cultural se puede hallar:

Desde el displacer más absurdo "ah, maldita sea", hasta "oh, sí, eso es", porque yo he llegado a sentir algo así, como un encuentro místico con el universo, por ejemplo, estando en escena o haciendo un ejercicio, si como que dejo de pensar y el cuerpo no existe más para mí, eso es uff... así es el placer (I:09/GrTe/Tec:Ep/R:22/G:F).

La práctica es un escenario desde el cual se puede vivenciar esta relación placer/ dolor, el espacio desde donde ellos la pueden re-crear. En este sentido, Nietzsche (1998: 38) había planteado que: «El propio ser, creador, se creó el aprecio y el desprecio, el placer y el displacer. El cuerpo creador se creó el espíritu como brazo de su voluntad». Placer que se expresa con violencia y que hace parte del dolor o donde el dolor hace parte del placer. Sin embargo, en ocasiones el dolor se juega en oposición al placer, en otras se integra a él, hace parte de él, es un medio para expresar desde las prácticas los que ellos son, aquello de lo que son capaces.

Pero el dolor también puede aparecer en el encuentro amoroso, en ese ejercicio de posesión del otro, de sometimiento frente a otro ajeno a mi cuerpo. Expresión de brusquedad y fuerza pero igualmente de comunicación entre unos cuerpos. Es un movimiento donde el deseo se liga al dolor y el placer, a la satisfacción de alcanzar lo deseado tal como se lo preguntara un joven: «¿Qué sería del dolor sin el placer?» (I:06/Gr:Dm/ Tec:Ep/R: 07/G:M). Es la convergencia de dolor y placer, donde se mixtura lo uno y lo otro, y donde se siente la mayor libertad y la mayor incertidumbre por no saber en qué lugar se está. Un híbrido que se vivencia de diferentes formas. Imágenes que representan el placer que ofrece la práctica y al mismo tiempo el objeto productor de placer (el cuchillo) en la laceración, en esa práctica dolorosa del placer.

La relación con el dolor también está dada desde la posibilidad de dominio del dolor, en relación con un propósito vinculado con su práctica, de encontrar una finalidad al dolor. Nietzsche (2000: 182) afirmaba que: «El hombre, que es el animal más valiente y más habituado a sufrir, no niega el dolor en sí; incluso lo quiere y lo persigue, siempre y cuando se le muestre que éste tiene sentido, una finalidad». Superar el dolor que los limita y alcanzar lo deseado porque se considera: «Entre más sufre uno haciendo ejercicio, o por lo menos yo, entre más sufro haciendo ejercicio, entre mas me cuesta, mejor me siento» (I:02/Gr:Cp/Tec:Ep/R:147/G:M). Una búsqueda que implica dolor, sentir el dolor.

Tenemos entonces que la relación placer/dolor se nos presenta desde la perspectiva de los jóvenes, como una mixtura de emociones vivenciadas en medio de la práctica. Integrar el dolor al placer hace que éste se vuelva deseable y no se convierta en un límite o en un obstáculo. Aquí, como en otros pasajes, la hibridez y la ambigüedad se convierten en la manera de instituir unas nuevas significaciones imaginarias, que mezclan 
aquello que se consideraba opuesto. Hacer del dolor algo placentero, hace del dolor una vivencia a cual se enfrentan cuando se desafían al límite como posibilidad abierta, como incertidumbre; por ello, la búsqueda de su dominio, que es lo que permite enfrentarlo, habituarse a él y poder soportarlo.

\section{CONCLUSIONES}

Las significaciones imaginarias de deseo nos muestran cómo a pesar de que analíticamente se pueda establecer una diferenciación o optar por dos caminos (carencia y potencia) para el deseo, en la vida cotidiana de los jóvenes, en el mundo de la vida, estas significaciones se encuentran en mixtura. De ahí la importancia de situar, de ubicar en contexto este tipo de reflexiones, en donde la emergencia de significaciones imaginarias no significa la negación de las otras, ya que son un poco de ellas y en algunas ocasiones su campo de posibilidad. En este contexto, el deseo se satisface, ya no sólo cuando se suple la necesidad, sino también cuando se obtiene reconocimiento por haberse desafiado al límite, por haberse comprometido con una práctica voluntaria.

Mixtura de significaciones que hacen que dos perspectivas irreconciliables en teoría se acerquen, haciendo de la satisfacción un híbrido, un fragmento de inmanencia, configurado también desde la carencia. El deseo se convierte en un proceso de producción con necesidades que lo socavan y con placeres que lo colman, con temporalidades donde la satisfacción se aplaza o donde se satisface a sí misma "aquí y ahora", cuando los jóvenes se desafían al límite y desafiándose vivencian múltiples intensidades de placer y obtienen por ello reconocimiento.

Placeres atópicos que se viven desde el erotismo, desde el hacer y desde el dolor; placeres convertidos en una manera de poblar y de habitar unas corporeidades con intensidades múltiples, con entramados instituidos de significaciones que encarnan la carencia; pero que hacen igualmente de las prácticas de subjetivación, los espacios de vivenciación de la potencia, convirtiendo el cuerpo en el escenario para la configuración de lo instituyente.

El deseo traza la línea de fuga por la que huyen las singularidades, las multiplicidades, las convergencias y los puntos de encuentro; por tanto, tal como lo planteara Camille Doumolié (2005: 301), «No existe nada que sea más materialista y carnal que él, mas al mismo tiempo proyecta los espíritus, los cuerpos, los grupos sociales [para nuestro caso los jóvenes], en ese espacio abstracto en que los astros, los animales y los hombres se encuentran». Como lo expresara en un fragmento de un poema una joven prácticante de capoeira, "Únicamente mi corazón sabe realmente quién soy, y lo único y verdadero e incambiable en mí, es que nunca te dejaré, aunque pase mil veces por el dolor" (I:01/ Gr:Cp/Tec:Di/R:1/G:F).

\section{REFERENCIAS BIBLIOGRÁFICAS}

Bauman, Z (2004). La sociedad sitiada. Buenos Aires: Fondo de Cultura Económica. Bauman, Z. (2003). Trabajo, consumismo y nuevos pobres. Barcelona: Gedisa. Bataille, G. (2002). El erotismo. Barcelona: TusQuets Editores. 
Creswell, J. W. (1998). Qualitative inquiry and research design. Choosing among five traditions. California: Thousand Oaks, Sage publications.

Deleuze, G., Guattari, F. (2004). Mil mesetas. Capitalismo y esquizofrenia. Valencia: Pre-textos. Deleuze, G., Guattari, F. (1995). El Antiedipo. Capitalismo y esquizofrenia. Buenos Aires: Paidós. Domoulié, C. (2005). O desejo. Petrópolis: Voces.

Elias, N. (1999). Sociología fundamental. Barcelona: Gedisa.

Elias, N. (1997). Sobre el tiempo. México: Fondo de Cultura Económica.

Feixa, C. (2000). Generación @: La juventud en la era digital. Revista Nómadas, n. 13, 76-91.

Foucault, M. (1987). La historia de la sexualidad III. La inquietud de sí. México: Siglo XXI.

Foucault, M. (1986). La historia de la sexualidad II. El uso de los placeres. México: Siglo XXI.

Foucault, M. (1984). Vigilar y castigar. México: Siglo XXI.

Foucault, M. (1979). Las palabras y las cosas. Una arqueología de las Ciencias Humanas. México: Siglo XXI.

Freud, S. (2005a). La desfiguración onírica. Web: http://psikolibro.webcindario.com/entrafreud.htm.

Freud, S. (2005b). La interpretación de los sueños. Web: http://psikolibro.webcindario.com/entrafreud.htm

Guattari, F. \& Rolnik, S. (2005). Micropolítica. Cartografias del deseo. Petrópolis: Vozes.

Hurtado, D. (2008). La configuración: un recurso para comprender las significaciones imaginarias". Revista Latinoamericana de Ciencias Sociales, Niñez y juventud, v. 6, n. 1., 81-110.

Hammersley, M; Atkinson, P. (1994). Etnografía. Métodos de investigación. Barcelona: Paidós.

Lacan. J. (1997). Seminario VII. Barcelona: Paidós.

Leccardi, C. (2002). Tiempo y construcción biográfica en la "sociedad de la incertidumbre". Reflexiones sobre las mujeres jóvenes. Revista Nómadas, n. 16, 42-50.

Margullis, M. \& Urresti, M. (1998). La construcción social de la condición juvenil. Viviendo a toda. Jóvenes, territorios culturales y nuevas sensibilidades (pp. 3-21). Bogotá: Universidad Central, Siglo del hombre.

Murcia, N. \& Jaramillo, L. (2000). Investigación cualitativa. La complementariedad etnográfica. Armenia: Kinesis.

Nietzsche, F. (2000). Genealogía de la moral. Santafé de Bogotá: Editorial Esquilo. (1998). Así hablaba Zaratustra. Santafé de Bogotá: Panamericana. (1947). Más allá del bien y del mal. Buenos Aires: Aguilar.

Sartre, J. (1993). El ser y la nada. Ensayo de ontología fenomenológica. Barcelona: Altaya.

Serrano, J. F. (2004). Menos querer más de la vida. Concepciones de vida y muerte en jóvenes urbanos. Bogotá: Universidad Central, Siglo del hombre.

Spinoza, B. de. (1985). Ética demostrada según el orden geométrico. México: Fondo de cultura Económica.

Taylor, S. J. \& Bogdan, R. (1998). Introducción a los métodos cualitativos de investigación. Barcelona: Paidós. 
